\title{
Effectiveness and Safety of Bronchial Thermoplasty in Severe Asthma in Clinical Practice in Spain
}

\author{
Luis Puente-Maestu ${ }^{a-c}$ Milagros Llanos Flores ${ }^{a, c}$ Paola Benedetti ${ }^{a, c}$ \\ Ingrid Frías Benzant ${ }^{a} \quad$ Alicia Oliva Ramos ${ }^{a, c} \quad$ Julia García de Pedro ${ }^{a-c}$ \\ Pilar Sanz Sanz ${ }^{a}$ Javier García-López ${ }^{\text {a-c }}$ \\ a Hospital General Universitario "Gregorio Marañón," Servicio de Neumología, Madrid, \\ Spain; ${ }^{b}$ Facultad de Medicina de la Universidad Complutense de Madrid, Madrid, Spain; \\ 'Instituto de Investigación Sanitaria "Gregorio Marañón", Madrid, Spain
}

\section{What Is It about?}

- Bronchial thermoplasty is a minimally invasive treatment for asthma consisting of the thermal ablation of the bronchial smooth muscle by radiofrequency. In the present study, we describe the real-life experience with this therapy in a single center in Spain. On average, patients' symptoms improved remarkably, the number of exacerbations was reduced by $75 \%$, and the number of admission to the hospital was reduced by $33 \%$ in 1 year. The treatment allowed an average reduction in oral corticosteroids of $4 \mathrm{mg} / \mathrm{day}$, which may be clinically relevant, although it was statistically nonsignificant. The most important side effect was severe exacerbations of asthma immediately after the procedure that occurred in $11 \%$ of the treatments.

\section{Keywords}

Bronchoscopy · Radiofrequency · Exacerbations · Asthma admission · Bronchoscopy complications · Asthma control

\section{Abstract}

Background: Bronchial thermoplasty (BT) is a minimally invasive procedure consisting of application of thermal energy into the airways to produce ablation of the hypertrophic smooth muscle. It was approved for use in moderate-severe asthma in Spain in 2010. Objectives: The aims of the present study are to analyze the effectiveness and the safety of BT in clinical practice in our center. Methods: Participants had a confirmed diagnosis of severe asthma and poor control without therapeutic alternative. Effectiveness was measured by comparing exacerbations, admissions rates, asthma control, and medication 1 year prior and 1 year after BT was completed. All complications appearing during the procedure and in the first year were re- 
corded. Results: Patients had a mean age of 51 (SD 8) years and were predominantly female (17/23). The average number of activations per patient was 147 (16). The number of severe exacerbations was reduced by $75 \%(p<0.001)$. A 38\% reduction in admissions per year was also observed ( $p=0.03$ ). The Asthma Control Test improved by $7.1(3.7)$ points $(p=0.018)$. Before BT, the dose of inhaled corticosteroids was $1,621(1,015) \mu \mathrm{g}$ of budesonide-equivalent and the dose of oral corticosteroids was 15 (13) $\mathrm{mg}$ of prednisone-equivalent. There was a reduction in $430(731) \mu \mathrm{g}$ of budesonide-equivalent $(p=0.02)$ and $4(11) \mathrm{mg}$ of prednisone $(p=0.094)$. No changes in lung function were observed. Complications were related mostly to exacerbation of asthma in the days following the procedure. Conclusions: BT is effective and safe for severe uncontrolled bronchial asthma in real clinical practice.

(C) 2018 The Author(s)

Published by S. Karger AG, Basel

\section{Introduction}

Asthma prevalence in Spain varies between 3 and 10\% depending on the epidemiological criteria used [1]. In most patients, the disease is well controlled with inhaled therapy; however, in $5-10 \%$ of the asthmatic population, it is refractory to current treatment [2, 3]. Asthma patients who are refractory to treatment suffer a significant morbidity and disability despite using multiple drugs [4] and represent a substantial burden for health care services [5, 6].

The American Thoracic Society and European Respiratory Society define severe asthma as "asthma that requires treatment with high dose of inhaled corticosteroids (ICS) (i.e. > 800 $\mu$ g budesonide or equivalent) plus a second drug (and/or systemic CS) to prevent it from becoming uncontrolled or which remains uncontrolled despite this therapy in patients with a correct diagnosis of asthma and their comorbidities identified and treated" [7]. In these patients, phenotype-oriented treatments to modulate $\mathrm{Th}_{2}$ inflammatory response are effective in controlling symptoms and exacerbations; however, not all patients eligible for these therapies will achieve the desired control [3, 8-10]. Bronchial thermoplasty (BT) has proven an effective therapeutic option for patients with a nonallergic, noneosinophilic (non- $\mathrm{Th}_{2}$ ) type inflammation asthma phenotype [9-11]. Furthermore, BT has shown similar efficacy in patients with other asthma phenotypes and airway smooth muscle hypertrophy $[9,10]$. For non- $\mathrm{Th}_{2}$ severe asthma, BT can be a first option for patients with persistent symptoms after failure of triple therapy with high-dose ICS plus long-acting beta- 2 agonists (LABA) and tiotropium, before the use of oral corticosteroids (OCS). BT can also be considered an alternative therapy for patients with allergic or eosinophilic asthma who had an inadequate response to initial biologic therapy $[9,10]$.

BT is a minimally invasive procedure consisting of the application of thermal energy into the airways with the purpose of ablating the distinctive hypertrophic smooth muscle in severe asthma patients [12]. It was approved for use in moderate-severe asthma in Spain in 2010. Thermal energy is applied through the Alair ${ }^{\circledR}$ system (Boston Scientific, Natick, MA, USA) [12]. The catheter is introduced through the working channel of a flexible bronchoscope. The distal tip contains an extendable, 4-electrode basket that is deployed in accessible airways [12].

The objectives of the present study are to analyze the effectiveness and safety of BT under conditions of actual clinical practice, comparing the baseline situation of the patients submitted to this intervention in our center between June 2013 and September 2015 with the situation 1 year after the procedure; analyzing asthma control, reduction of treatment with ICS and OCS, number of severe exacerbations and hospital admissions, changes in lung function, and complications. 


\section{Methods}

This is a post-authorization cohort study. Inclusion criteria were a confirmed diagnosis of severe asthma [7], a history of 2 or more exacerbations requiring emergency assistance or hospital admission in the previous year, and poor symptomatic control defined as an Asthma Control Test (ACT) score of less than 20 points. Patients with nasal polyposis, allergic sinusitis, or gastroesophageal reflux were not considered candidates for BT if these conditions were not receiving adequate treatment. Patients who had vocal cord dysfunction, tracheal stenosis, or diffuse bronchiectasis on CT scan were excluded. Likewise, patients who had required admission to the intensive care unit in the previous year, were pregnant, had a peacemaker, or could not tolerate the bronchoscopy procedure were considered as unqualified for BT. Compliance with the long-term controller medication was verified by a questionnaire [13]. Candidates for available biological therapies according to ours or the referral center protocol were first offered this treatment. Patients who were receiving these therapies without achieving the desired control and were considered candidates for BT were also included.

From June 2013 to September 2015, we enrolled 23 patients referred to our center for BT and with a total follow-up of at least 1 year. The study was approved by the research ethics committee of our hospital and all subjects gave their written informed consent to participate.

Patients were scheduled for 3 procedures performed at least 3 weeks apart. The treatment was administered by a team of skilled bronchoscopists licensed by the training program of the manufacturer (which includes theoretical training, visits to centers with experience, and 10 sessions of the technique supervised by experts). BT was performed with the Alair ${ }^{\circledR}$ system (Boston Scientific, Natick, MA, USA) as described in the literature [14]. The procedures were done under general anesthesia with the patient intubated. Three days prior to each session, the patients received $50 \mathrm{mg}$ of oral prednisone and 30-90 min before each session $5 \mathrm{mg}$ of nebulized salbutamol. They all remained hospitalized overnight. In case the patient had suffered a recent moderate or severe exacerbation, the procedure was postponed for 6 weeks after its resolution. The protocol consisted of a complete initial evaluation, at which it was decided whether the patients were eligible for BT, and 3 additional visits, about 2 weeks before each session, to confirm clinical stability and to schedule the procedure. One, two and seven days after every discharge, the participants were contacted by telephone. The routine management of the patients after the procedure was carried out by their referring physicians; however, patients and physicians were contacted by phone at 2, 6, and 12 months to inquire about asthma symptoms, exacerbations, medication, adverse effects and perform the ACT. Post-bronchodilator spirometry (patients' treatment was not stopped for the test) was done at the initial evaluation and 1 year after the last BT session. Both tests were performed in a stable period defined as 6 weeks after the resolution of the last asthma exacerbation.

Exacerbations requiring an increase $>3$ days of at least $5 \mathrm{mg}$ of prednisone or equivalent dose of other systemic corticosteroids were recorded. The doses of ICS and OCS are the mean doses in the 6 weeks prior to the inclusion and 1 year after the procedure visits. They were converted to budesonide- and prednisone-equivalents, respectively.

\section{Statistical Analysis}

Effectiveness was analyzed only in the patients who completed the BT procedure (i.e., completed the 3 sessions); however, all BT sessions were included in the safety analysis. The variables are described as mean and standard deviation or proportions and standard error. Comparisons were carried out using the $t$ test for paired samples or the Wilcoxon rank test if normal distribution could not be assumed. Correlations were sought by the Spearman rho 


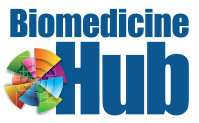

Table 1. Baseline characteristics of the population

(C) 2018 The Author(s). Published by S. Karger AG, Basel www.karger.com/bmh

Puente-Maestu et al.: Thermoplasty in Severe Asthma

\begin{tabular}{lc}
\hline Variable & Mean (SD) \\
\hline $\mathrm{FEV}_{1}, \%$ predicted & $79(17)$ \\
Age, years & $51(8)$ \\
ACT score & $7.2(1.5)$ \\
Severe exacerbations in the previous year & $4.5(4.1)$ \\
Hospital admissions in the previous year & $0.85(1.3)$
\end{tabular}

ACT, Asthma Control Test.

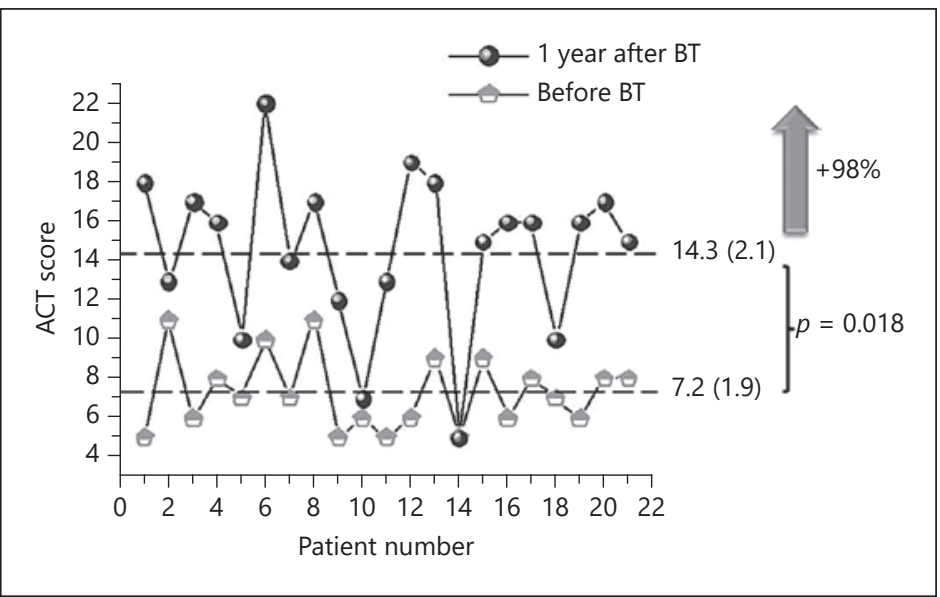

Change in disease control after bronchial thermoplasty (BT). ACT, Asthma Control Test.

coefficient. A probability of the null hypothesis (no differences between before and after) $<0.05$ was considered significant. Three points were considered as the clinically relevant difference in ACT [15].

\section{Results}

Of the 23 patients initially included, 2 did not complete the treatment. One of them decided to drop out because she had to move abroad and the other one because she had a severe exacerbation after the first session that needed noninvasive ventilation. The remaining 21 patients (Table 1 ) were predominantly female (15 out of $21,71.4 \%$ ) of middle age, 51 (8) years, ranging from 25 to 68 years old. One patient was an active smoker $(4.7 \%)$ and 6 were ex-smokers for more than 1 year (28.6\%). Before BT, all the participants were on LABA and ICS. The average baseline dose of ICS was $1,621(1,015) \mu \mathrm{g}$ of budesonide-equivalent. Nineteen $(83 \%)$ were on tiotropium, 16 (76\%) were using montelukast, 14 (66\%) were receiving OCS as part of their regular treatment with an average dose of 15 (13) mg of prednisone-equivalent, 7 (33\%) were taking theophyllines, 4 (19\%) received nebulizations of $5 \mathrm{mg}$ of salbutamol and ipratropium bromide $500 \mathrm{mg} 3$ times a day as additional control treatment, and 3 (14\%) were on omalizumab $300 \mathrm{mg}$ every 15 days ( 2 additional patients had been withdrawn from this medication because of inefficacy before referring them to BT). In 2 patients, $\mathrm{FEV}_{1}$ was $<65 \%$, in one of them it was $36 \%$. The mean number of activations per patient was 147 (16), 42 (4) in the lower right lobe, 35 (3) in the lower left lobe, and 67 (5) in the upper lobes. We found a Spearman correlation of 0.255 and $0.229(p=0.200$ and 0.239$)$ between the total 
Fig. 2. Change in severe exacerbations after bronchial thermoplasty (BT).

Fig. 3. Change in hospital admissions after bronchial thermoplasty (BT).
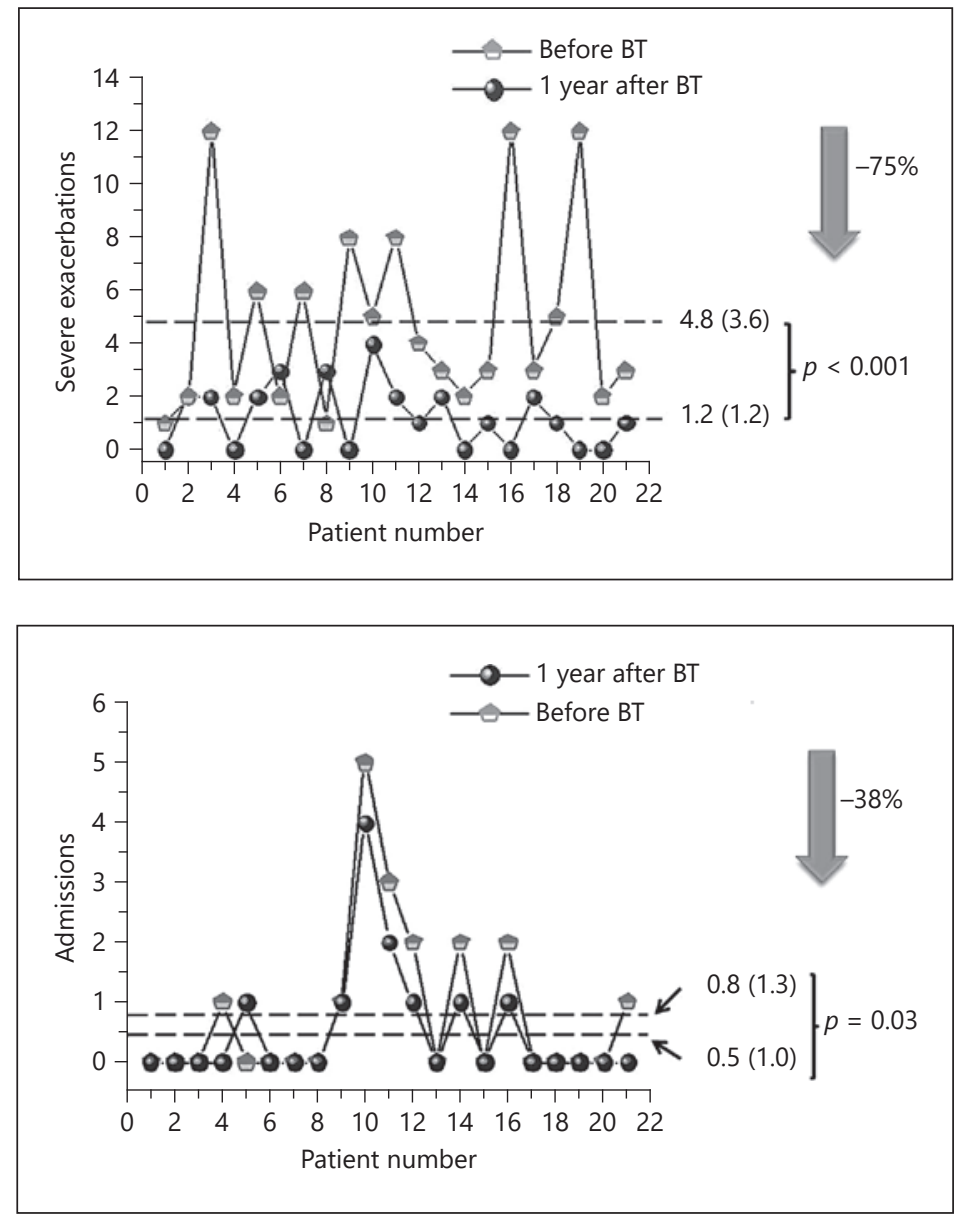

number of activations and the absolute reduction in severe exacerbations or hospitalizations, respectively.

ACT improved by 7.1 (3.7) points ( $p=0.018$ ) (Fig. 1). None of the patients had a worse ACT at 1 year and in 16 individuals (76\%), the gain exceeded the clinically relevant difference of 3 points. The number of severe exacerbations was also reduced by $75 \%$ (9\%) (Fig. 2), with a mean reduction of $3.5(4.0)$ per patient-year $(p<0.001)$. Only in 3 patients severe exacerbations increased or remained the same as in the previous year (Fig. 2). A reduction of $38 \%$ $(35 \%)$ in the number of admissions was observed as well (Fig. 3) with a mean reduction of $0.3(0.6)$ per patient-year $(p=0.03)$. In 7 patients the number of admissions was reduced and 1 patient had 1 admission more after BT than in the year before the treatment. In the other patients (most of them with no admissions in the previous year) there were no changes.

At 1 year, 4 (28\%) of the 14 patients on OCS at baseline were not using OCS, 4 (28\%) had reduced the dose (by $80,50,33$, and $20 \%$, respectively), 3 (21\%) were on the same dose, and $3(21 \%)$ needed a higher dose (Table 2). One additional patient, who was not taking OCS at visit 1 , was using them after the treatment (average dose $1.6 \mathrm{mg}$ ). The mean reduction of OCS was of 4 (11) $\mathrm{mg}(p=0.094)$. Treatment with theophyllines was discontinued in 4 patients, and the dose was reduced in 2 . There were no changes in patients receiving leukotriene antagonists or omalizumab. Two of the 4 patients who were being treated with nebulized medication had suspended it. There were no changes in the lung function with a mean difference of $-0.5(2.77 \%)$ of predicted $\mathrm{FEV}_{1}$. 
Table 2. Use of corticosteroids at baseline and 1 year after BT (c) 2018 The Author(s). Published by S. Karger AG, Basel www.karger.com/bmh

Puente-Maestu et al.: Thermoplasty in Severe Asthma
Table 3. Adverse effects of bronchial thermoplasty $(n=65$ sessions)

\begin{tabular}{lcc}
\hline & Mean (SD) \\
\cline { 2 - 3 } & baseline & 1 year after BT \\
\hline Budesonide-equivalent, $\mu \mathrm{g}$ & $1,641(1,014)$ & $1,191(701)$ \\
Prednisone-equivalent, $\mathrm{mg}$ & $15(13)$ & $11(10)$ \\
\hline
\end{tabular}

BT, bronchial thermoplasty; SD, standard deviation.

\begin{tabular}{ll}
\hline Complication & $\begin{array}{l}\text { Absolute (relative) } \\
\text { frequency }\end{array}$ \\
\hline Asthma exacerbation & $7(10.6 \%)$ \\
$\quad$ Delayed discharge $<7$ days & $6(9.1 \%)$ \\
$\quad$ Delayed discharge $\geq 7$ days + NIMV & $1(1.5 \%)$ \\
Atelectasis & $2(3.0 \%)$ \\
Chest pain & $6(9.2 \%)$ \\
Severe hemoptysis (after 23 days) & $1(1.5 \%)$
\end{tabular}

NIMV, noninvasive mechanical ventilation.

The most frequent complications were severe asthma exacerbations in the days following the bronchoscopy (Table 3). One case required noninvasive mechanical ventilation. We had a case of major hemoptysis 23 days after the last session in a patient treated with clopidogrel and aspirin due to a transient ischemic attack (which was discontinued for BT and restarted after the procedure). She had nonsymptomatic isolated bronchiectasis on chest CT scan.

\section{Discussion}

The present article describes our clinical practice and experience with BT. We found that BT improved symptoms and reduced severe exacerbations in a magnitude similar to the randomized controlled trials "Asthma Intervention Research Trial" (AIR) AIR-1 and AIR-2 $[11,16]$ - which were the basis for the Food and Drug Administration approval -, other observational studies in different countries [17-19], and a recently published cohort of 190 patients (PAS-2) [20].

Our patients have a comparable lung function to that of the AIR-2 and PAS-2 participants - allowing for small divergences as percent predicted values due to the use of different reference values $[11,20,21]$ - however, they were clinically more severe than the AIR-2 and PAS-2 patients $[11,20]$, with more severe exacerbations before BT treatment.

We observed a moderate sparing effect of BT on medication in our patients. ICS were reduced by $430(720) \mu \mathrm{g}(p<0.02)$ of budesonide-equivalent. Similarly to the PAS- 2 study [20], we saw a tendency towards a reduction of the OCS ( $p=0.094)$, with 8 out of the 14 patients (57\%) who were using OCS at the initial visit being able to stop or reduce the dose; however, this effect was not consistent in all the participants, resulting in a modest average reduction of 4 (11) $\mathrm{mg}(p=0.094)$; the study was not designed to look into the factors differentiating those who could and those who could not reduce OCS and the sample was small to achieve sufficient statistical power; thus, the finding can only be taken as a hypothesis-gener- 
ating observation. Finally, there was also a reduction in the use of theophyllines and nebulizer bronchodilators.

Regarding omalizumab, in the few patients in whom its use was combined with BT, it appeared to improve asthma control, proposing again the hypothesis that BT may be an add-on option for patients who do not respond satisfactorily to biological treatments.

The proportion of adverse effects in our study was slightly lower than in the AIR-2 and PAS-2 studies (Table 3). As we did not see respiratory tract infections, the risk of exacerbations was slightly lower, and the incidence of atelectasis and hemoptysis was similar $[11,20]$. Our patients occasionally reported mild chest pain for a few days after the procedure, with no radiological or long-lasting clinical consequences, which was managed with nonsteroidal anti-inflammatory drugs. This side effect was neither described in AIR-2 [11] nor in PAS-2 [20].

The mechanisms that underlie a better asthma control after BT remain unclear. Several studies have shown that there is a significant reduction of the smooth muscle [22-25]; this is still considered the main mechanism of action, but the smooth muscle also participates in the immune regulation of the bronchial wall $[26,27]$, and some studies suggest that BT can modify the bronchial and systemic inflammatory profile [28, 29]. Moreover, some work suggests that BT can decrease submucosal nerve endings, which are known to be involved in the regulation of smooth muscle tone and bronchial hyperreactivity [24]. Several studies are currently underway to evaluate the molecular, cellular, and pathological changes that may occur after treatment with BT [30-32].

The limitations of this study are the relatively small number of patients included, which does not allow establishing relationships to define predictors of response to BT. Several studies are now in course aimed to identify such factors $[33,34]$. Our study is an observational one, which may have led to certain bias when interpreting effectiveness and safety; nonetheless, as we have already mentioned, the results are very similar to other observational studies [17-20] and to the randomized controlled trials AIR-1 and AIR-2 [11, 16], the latter blinded and placebo-controlled, thus it can be considered as an open-label confirmatory study in a different setting and in actual clinical practice conditions. We did not see improvement in $\mathrm{FEV}_{1}$; however, the effects on lung function are very difficult to measure in a study like the present one, since the participants had severe asthma and we considered it not appropriate to withdraw the medication. Baseline lung function, therefore, was measured while taking their regular medication. We calculated the average dose of medication the patients were using during the 6 weeks before the first and last visits, but not the total dose used in the previous year. We feel that 6 weeks is a representative period of the medication need of the patients, particularly because the enrollment visit was not determined by the investigators and the 1-year visit was predetermined at the enrollment of the patients and did not depend on their control status. Moreover, the medication-sparing effect in a longer period of time, if any, would have been even higher since there was an important reduction (by 75\%) in moderate-severe asthma exacerbations and the control of the patients, as measured by ACT, had markedly improved after BT.

\section{Conclusions}

In patients with very severe asthma, BT is as effective in clinical practice as in clinical trials, which generally included less severe patients. In our practice it had some medicationsparing effect that was very relevant (withdraw of OCS) for a selected number of patients. It is a safe technique; however, based on our experience with 1 case, we recommend special caution in patients with bronchial dilations, even if asymptomatic. 


\section{Disclosure Statement}

During the period of the study, Luis Puente-Maestu received fees from Boston International for talks in sponsored conferences. The other authors do not present any conflict of interest with this paper.

\section{References}

1 Urrutia I, Aguirre U, Sunyer J, Plana E, Muniozguren N, Martinez-Moratalla J, Payo F, Maldonado JA, Anto JM: Changes in the prevalence of asthma in the Spanish cohort of the European Community Respiratory Health Survey (ECRHS-II). Arch Bronconeumol 2007;43:425-430.

2 Plaza Moral V; Comité Ejecutivo de GEMA: GEMA (4.0). Guidelines for Asthma Management. Arch Bronconeumol 2015;51(suppl 1):2-54.

3 Global Initiative for Asthma: Global Strategy for Asthma Management and Prevention. Available from: www. ginasthma.org. 2016.

4 Slavin RG, Haselkorn T, Lee JH, Zheng B, Deniz Y, Wenzel SE: Asthma in older adults: observations from the epidemiology and natural history of asthma: outcomes and treatment regimens (TENOR) study. Ann Allergy Asthma Immunol 2006;96:406-414.

5 Godard P, Chanez P, Siraudin L, Nicoloyannis N, Duru G: Costs of asthma are correlated with severity: a 1-yr prospective study. Eur Respir J 2002;19:61-67.

6 Martinez-Moragon E, Serra-Batlles J, De DA, Palop M, Casan P, Rubio-Terres C, Pellicer C: Economic cost of treating the patient with asthma in Spain: the AsmaCost study. Arch Bronconeumol 2009;45:481-486.

7 Chung KF, Wenzel SE, Brozek JL, Bush A, Castro M, Sterk PJ, Adcock IM, Bateman ED, Bel EH, Bleecker ER, Boulet LP, Brightling C, Chanez P, Dahlen SE, Djukanovic R, Frey U, Gaga M, Gibson P, Hamid Q, Jajour NN, Mauad T, Sorkness RL, Teague WG: International ERS/ATS guidelines on definition, evaluation and treatment of severe asthma. Eur Respir J 2014;43:343-373.

8 Menzella F, Galeone C, Bertolini F, Castagnetti C, Facciolongo N: Innovative treatments for severe refractory asthma: how to choose the right option for the right patient? J Asthma Allergy 2017;10:237-247.

9 Blaiss MS, Castro M, Chipps BE, Zitt M, Panettieri RA Jr, Foggs MB: Guiding principles for use of newer biologics and bronchial thermoplasty for patients with severe asthma. Ann Allergy Asthma Immunol 2017;119:533540 .

10 Zervas E, Samitas K, Papaioannou AI, Bakakos P, Loukides S, Gaga M: An algorithmic approach for the treatment of severe uncontrolled asthma. ERJ Open Res 2018;4.

11 Castro M, Rubin AS, Laviolette M, Fiterman J, De Andrade LM, Shah PL, Fiss E, Olivenstein R, Thomson NC, Niven RM, Pavord ID, Simoff M, Duhamel DR, McEvoy C, Barbers R, Ten Hacken NH, Wechsler ME, Holmes M, Phillips MJ, Erzurum S, Lunn W, Israel E, Jarjour N, Kraft M, Shargill NS, Quiring J, Berry SM, Cox G: Effectiveness and safety of bronchial thermoplasty in the treatment of severe asthma: a multicenter, randomized, doubleblind, sham-controlled clinical trial. Am J Respir Crit Care Med 2010;181:116-124.

12 Laxmanan B, Hogarth DK: Bronchial thermoplasty in asthma: current perspectives. J Asthma Allergy 2015;8: 39-49.

13 Plaza V, Fernandez-Rodriguez C, Melero C, Cosio BG, Entrenas LM, de Llano LP, Gutierrez-Pereyra F, Tarragona E, Palomino R, Lopez-Vina A: Validation of the 'Test of the Adherence to Inhalers' (TAI) for Asthma and COPD Patients. J Aerosol Med Pulm Drug Deliv 2016;29:142-152.

14 Cox G, Miller JD, McWilliams A, Fitzgerald JM, Lam S: Bronchial thermoplasty for asthma. Am J Respir Crit Care Med 2006;173:965-969.

15 Schatz M, Kosinski M, Yarlas AS, Hanlon J, Watson ME, Jhingran P: The minimally important difference of the Asthma Control Test. J Allergy Clin Immunol 2009;124:719-723.

16 Cox G, Thomson NC, Rubin AS, Niven RM, Corris PA, Siersted HC, Olivenstein R, Pavord ID, McCormack D, Chaudhuri R, Miller JD, Laviolette M: Asthma control during the year after bronchial thermoplasty. N Engl J Med 2007;356:1327-1337.

17 Watchorn DC, Sahadevan A, Egan JJ, Lane SJ: The efficacy of bronchial thermoplasty for severe persistent asthma: the first national experience. Ir Med J 2016;109:406.

18 Nong Y, Su N, Lin J, Chen X, Zhao Q, Han C, Zhang Y, Zhang X, Ren Z, Li X: Effectiveness and safety of bronchial thermoplasty in patients with severe asthma. Zhonghua Jie He He Hu Xi Za Zhi 2016;39:177-182.

19 Bicknell S, Chaudhuri R, Lee N, Shepherd M, Spears M, Pitman N, Cameron E, Cowan D, Nixon J, Thompson J, McSharry C, Thomson NC: Effectiveness of bronchial thermoplasty in severe asthma in 'real life' patients compared with those recruited to clinical trials in the same centre. Ther Adv Respir Dis 2015;9:267-271.

20 Chupp G, Laviolette M, Cohn L, McEvoy C, Bansal S, Shifren A, Khatri S, Grubb GM, McMullen E, Strauven R, Kline JN: Long-term outcomes of bronchial thermoplasty in subjects with severe asthma: a comparison of 3-year follow-up results from two prospective multicentre studies. Eur Respir J 2017;50:1700017. 
21 Quanjer PH, Tammeling GJ, Cotes JE, Pedersen OF, Peslin R, Yernault JC: Lung volumes and forced ventilatory flows. Report Working Party Standardization of Lung Function Tests, European Community for Steel and Coal. Official Statement of the European Respiratory Society. Eur Respir J Suppl 1993;16:5-40.

22 Pretolani M, Dombret MC, Thabut G, Knap D, Hamidi F, Debray MP, Taille C, Chanez P, Aubier M: Reduction of airway smooth muscle mass by bronchial thermoplasty in patients with severe asthma. Am J Respir Crit Care Med 2014;190:1452-1454.

23 Chakir J, Haj-Salem I, Gras D, Joubert P, Beaudoin EL, Biardel S, Lampron N, Martel S, Chanez P, Boulet LP, Laviolette M: Effects of bronchial thermoplasty on airway smooth muscle and collagen deposition in asthma. Ann Am Thorac Soc 2015;12:1612-1618.

24 Pretolani M, Bergqvist A, Thabut G, Dombret MC, Knapp D, Hamidi F, Alavoine L, Taille C, Chanez P, Erjefalt JS, Aubier M: Effectiveness of bronchial thermoplasty in patients with severe refractory asthma: clinical and histopathologic correlations. J Allergy Clin Immunol 2017;139:1176-1185.

25 Miller JD, Cox G, Vincic L, Lombard CM, Loomas BE, Danek CJ: A prospective feasibility study of bronchial thermoplasty in the human airway. Chest 2005;127:1999-2006.

26 Panettieri RA Jr, Kotlikoff MI, Gerthoffer WT, Hershenson MB, Woodruff PG, Hall IP, Banks-Schlegel S: Airway smooth muscle in bronchial tone, inflammation, and remodeling: basic knowledge to clinical relevance. Am J Respir Crit Care Med 2008;177:248-252.

27 Solway J, Irvin CG: Airway smooth muscle as a target for asthma therapy. N Engl J Med 2007;356:1367-1369.

28 Denner DR, Doeing DC, Hogarth DK, Dugan K, Naureckas ET, White SR: Airway inflammation after bronchial thermoplasty for severe asthma. Ann Am Thorac Soc 2015;12:1302-1309.

29 Ryan DM, Fowler SJ, Niven RM: Reduction in peripheral blood eosinophil counts after bronchial thermoplasty. J Allergy Clin Immunol 2016;138:308-310.

30 National Institutes of Health Clinical Center: Bronchial thermoplasty: effect on neuronal and chemosensitive component of the bronchial mucosa (BT-ASMN). NCT01839591. 2016.

31 National Institutes of Health Clinical Center: Study of physiopathological mechanisms and results of treatment with bronchial thermoplasty in severe asthma. NCT01974921. ClinicalTrials.gov. Bethesda, National Institutes of Health, 2013. https://clinicaltrials.gov/ct2/show/NCT01974921 (updated November 19, 2015). 2018.

32 ISRCTN Registry: Bronchial thermoplasty study: an observational study examining airway remodelling and repair in patients with severe persistent asthma treated with bronchial thermoplasty. ISRCTN94263922. http://www.isrctn.com/ISRCTN94263922 (accessed December 8, 2014). 2018.

33 National Institutes of Health Clinical Center: A prospective observational study of biopredictors of bronchial thermoplasty response in patients with severe refractory asthma (BTR Study) (BTR). NCT01185275. ClinicalTrials.gov. Bethesda, National Institutes of Health, 2010. https://clinicaltrials.gov/ct2/show/NCT01185275 (updated December 20, 2014). 2018.

34 Herth FJ, Niven R, Torrego A, Puente L, Facciolongo N, Novali M, Bicknell S, Gasparini S, Andreo F, Dheda K, Vortuba J, McMullen E, Nolan F: Bronchial thermoplasty (BT) global registry: trial design and current patient profile. Am J Respir Crit Care Med 2016;193:A3387. 